\title{
A review on implementation of meta-heuristic approaches for layout problems in dynamic business environment
}

\author{
Parveen Sharma* and Sandeep Singhal \\ Department of Mechanical Engineering, \\ National Institute of Technology Kurukshetra, \\ Kurukshetra-136119, Haryana, India \\ Email: parveen_6120052@nitkkr.ac.in \\ Email: Sandeep_singhal_reck@rediffmail.com \\ *Corresponding author
}

\begin{abstract}
Arrangement of the facilities on shop floor in industries termed as facility layout planning. It is a vital issue at the premature stage while designing a manufacturing structure because it affects the total manufacturing cost considerably. The dynamic environment is such an industrial condition in which flexibility exists in the demand of the product. The purpose of this research paper is to present a review on the implementation of meta-heuristics approaches for handling the problem of facility layout in a dynamic environment. Various meta-heuristic approaches which have been implemented in facility layout planning (FLP) are discussed briefly and the percent utilisation of different approaches is analysed in various time spans. Tabu search (TS), genetic algorithm (GA), particle swarm optimisation (PSO), and ant colony optimisation (ACO) are several typically used methods by researchers for layout optimisation. In the present study, \% utilisation of these algorithms has been analysed for different time span, ACO utilised by maximum researchers in the time span '2010-2015'. The present study also revealed GA has been executed by most of the researchers $(25 \%)$, whereas PSO $(8 \%)$ utilised by very least designers.
\end{abstract}

Keywords: dynamic environment; meta-heuristic; optimisation; facility layout planning; hybrid approaches.

Reference to this paper should be made as follows: Sharma, P. and Singhal, S. (2016) 'A review on implementation of meta-heuristic approaches for layout problems in dynamic business environment', Int. J. Multivariate Data Analysis, Vol. 1, No. 1, pp.6-27.

Biographical notes: Parveen Sharma is a $\mathrm{PhD}$ scholar in the Department of Mechanical Engineering at National Institute of Technology (NIT), Kurukshetra, Haryana, India and working in the area of industrial and production engineering. He obtained his BTech in Mechanical Engineering in 2009 from KUK and ME in Mechanical Engineering in 2011 from NITTTR, Chandigarh, India. His research interest includes facility layout planning and design, material handling, etc. He has about three years of teaching, research and professional experience. He has published about 20 research papers in various national and international conferences as well as in journals. 


\begin{abstract}
Sandeep Singhal is currently working as an Associate Professor in Department of Mechanical Engineering, National Institute of Technology (NIT), Kurukshetra, Haryana, India, an institution of national importance. Currently, he is the Chairman of ISTE, Haryana Chapter. He is a PhD from NIT, Kurukshetra. He has more than 25 years of teaching, research and professional experience and has authored more than 40 research papers in reputed national and international peer reviewed journals and conferences. He has authored a book on entrepreneurship. His areas of interest are SCM, ERP, TQM, entrepreneurship, facility management, etc. He has worked with AICTE and NBA the apex regulatory body for technical education in various capacities for seven years and was closely associated with Washington Accord. He has guided/guiding research scholars at MTech and $\mathrm{PhD}$ levels.
\end{abstract}

\title{
1 Introduction
}

In the industries practically there are several problems those crop up, and due to a competitive environment, it becomes very necessary to solve them optimally. For handling a problem up-to an optimal level, it generally requires algorithms, and if meta-heuristic involved in them, such optimisation falls under meta-heuristic optimisation. Some of them are as; GA, simulated annealing (SA), differential evolution (DE), ant colony optimisation (ACO), cuckoo search, bee algorithms, firefly algorithm, PSO, tabu search (TS), harmony search etc. According to Voss (2001) almost all the available meta-heuristic algorithms are likely suitable for global optimisation. These algorithms can be applied in various fields of research in academic as well as in industries. Present study, focuses on the review of different optimisation studies for facility layout problem using meta-heuristic algorithms. The problem of facility layout is not only associated with any specific field, it also directly affects the productivity of all kinds of industries like chemical, manufacturing, electronics, construction etc.

For an industry facility layout problem deals with arranging the available facilities in such a way to get the maximum utilisation from them. These facilities on the shop floor may be machines, departments, offices etc. The selected layout guides the proper flow of material and man power within the company. An improper layout will result in reduced productivity, increased tied up capital and in some cases it can lead the personnel being exposed to unnecessary physical material handling without any due cause. Between $20 \%$ to $50 \%$ of the entire operating costs and $15 \%$ to $70 \%$ of the total cost for a product is attributed to handling of material and at least $10 \%$ to $30 \%$ of these costs could have been saved if layouts were planned effectively (Sharma and Singhal, 2015; Sharma et al., 2012). The facility layout problem can be categorised into static and dynamic; in static facility layout problem (SFLP) the material flow constant over the entire time planning horizon (Ou-Yang and Utamima, 2013), whereas in dynamic facility layout problem (DFLP), a single layout is designed for each period of multi-period planning horizon. Ulutas and Islier (2015) solved DFLP in footwear industry. Hasani et al. (2015), Kheirkhah et al. (2015), Emami and Nookabadi (2013) also considered dynamic layout problem. If the available shop floor facilities are not properly laid out, such situation leads to higher work-in-process inventory, overloading to material handling equipments, longer queues etc. For overcoming such critical situation, the layout must be designed 
properly and should be optimised. Such layout helps in reducing the work-in-process inventory, improves material flow and leads to better utilisation of available work space (Şahin and Türkbey, 2009; Jajodia et al., 1992). According to Tompkins et al. (2003), for getting maximum productivity from the available resources, it is very necessary to utilise them optimally; it can save $30 \%-70 \%$ of manufacturing cost. A survey on FLP has been carried out by Drira et al. (2007) which defines that meta-heuristic plays a very imperative role in the optimisation of the layout problems. Some meta-heuristic approaches like TS, GA, PSO, ACO, etc. are used by a lot of researchers for optimisation of layout problems (Kundu and Dan, 2012; Şahin and Türkbey, 2009; Krishnan et al., 2008). Several studies have also explored a comparative analysis of these approaches, like de Alvarenga et al. (2000) compared TS and SA in case of a single row and multi-row facility layout problems.

The widespread importance of layout leads to predict the future perspectives of meta-heuristic optimisation for layout planning under dynamic environmental condition and also review these for the present scenario. Reviews on meta-heuristics for facility layout have also been demonstrated by Mavridou and Pardalos (1997), which discussed a numerous applications of SA and GA. Balakrishnan and Cheng (1998) presented a survey on dynamic facility layout algorithms. The review carried out so far by various researchers, are very effective, but none of them considered the '\% utilisation' of the meta-heuristics year by year, and also the analysis of up and down fall of the approaches separately year wise. In the present study, these optimisation approaches are examined on the basis of their application, and an effort is made to fulfil the above said research gap. The future trend of these considered approaches has also been predicted on the basis of mathematical charts. The paper is organised as first section represents introduction, in Section 2 briefly discussion on meta-heuristic in layout problem. Population-based search and single point search algorithms demonstrated in Sections 3 and 4 respectively. Other important meta-heuristic approaches for FLP discussed in Section 5. Future perception of meta-heuristic for FLP given in Section 6 followed by conclusions in Section 7.

\section{Meta-heuristic in layout problems}

Drira et al. (2007) presented 'resolution tree' for handling a layout problem, Figure 1 demonstrates it. According to them, FLP can be resolved by three approaches; exact methods, heuristic methods and with intelligent approaches. Approaches like branch and bound algorithm and dynamic programming come under exact methods. The heuristic methods can be subdivided into three approaches; construction and improvement heuristics, Meta-heuristics and Hybrid approaches. SA, TS, GAs and ACO come under meta-heuristics algorithms.

Optimisation of the layout problem using meta-heuristic are considered as meta-heuristic optimisation. A variety of meta-heuristic algorithms used for optimisation like cuckoo search, DE, ACO, GA, bee algorithms, firefly algorithm, particle swarm optimisation (PSO), TS, SA, harmony search etc. The meta-heuristics can be classified on the basis of their search techniques i.e., population-based search and single point-based search. GA and ACO falls under population-based category and on the other hand SA and TS comes in single point search algorithm category. 
Figure 1 Resolution tree for handling the layout problem

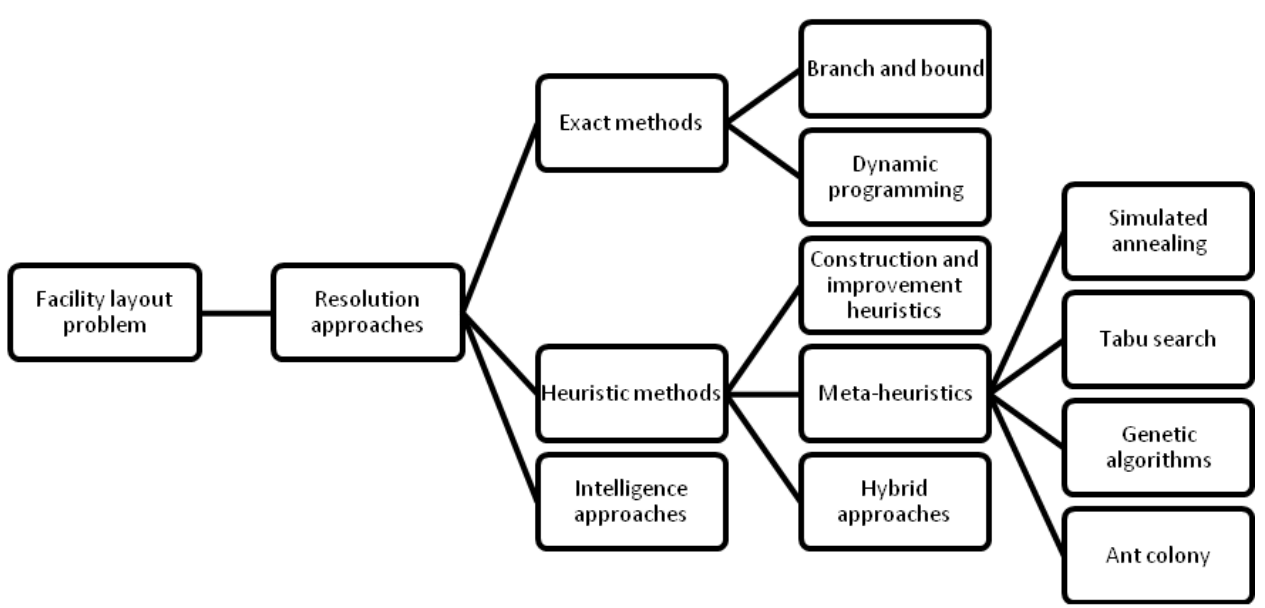

Source: Drira et al. (2007)

\section{Population-based search algorithm for facility layout}

\subsection{Genetic algorithm}

In the 1960s and 1970s, GA was developed by Holland (1992) and his collaborators. The GA is very popular and has a diverse range of applications in various fields. Crossover, recombination, mutation and selection are first used by Holland in the study of adaptive and artificial systems. Crossover, recombination, mutation and selection are four essential component of GA as a problem solution approach. The spirit of this algorithm involves the encoding of solutions as arrays of bits or character strings, the manipulation of these strings by genetic operators and a choice is based on their fitness to find a solution to a given problem. A study on hybrid multi-population GA for the DFLP is carried out by Pourvaziri and Naderi (2014). Pierreval et al. (2003) proposed an evolutionary approach to the design and organisation of manufacturing systems. Wu and Appleton (2002) optimised the block layout and aisle structure of layout using a GA. A GA for facility layout design in flexible manufacturing systems has been proposed by Rajasekharan et al. (1998). A multi-floor layout design model for dynamic cellular manufacturing system has been proposed by Kia et al. (2014). An efficient GA approach for facility layout problems has been suggested by Kothari and Ghosh (2014a). Zhang et al. (2014) applied GA in designing the functional area layout of railway logistics park. Zhang et al. (2002) considered a class of GA for multiple-level warehouse layout problems. A GA for cellular manufacturing design and layout has been suggested by $\mathrm{Wu}$ et al. (2007). It is observed that in the recent period GA has frequently been used by various researchers for the optimisation of the layout planning (Eklund et al., 2006; Gau and Meller, 1999; Ramkumar et al., 2009a; Wang et al., 2008a, 2880b; Delmaire et al., 1997; Kulkarni and Shanker, 2007). A biased random-key GA for the unequal area facility layout problem is studied by Gonçalves and Resende (2015). Caputo et al. (2015) demonstrated a safety-based process plant layout using GA. GA is used by Conway and Venkataramanan 
(1994) for handling the DFLP by considering the budget constraint. Different problem specific customised crossover and mutation operation were developed to achieve better efficiency of GA (Delmaire et al., 1997; Wu et al., 2007; Eklund et al., 2006; Ramkumar et al., 2009b; Wang et al., 2008a; Wu and Appleton, 2002; Phanden et al., 2012a, 2012b). Conway and Venkataramanan (1994) utilised GA to solve DFLP. Balakrishnan and Cheng (2000) applied GA to solve large sized problems by using point to point cross over to expand the search space (Moslemipour et al., 2012). GA has ability to solve different kinds of combinatorial optimisation problems. It also has ability to find global best solution. It can be easily combine with other algorithms. Disadvantages of GA; it is very slow as compare to other algorithms. The crossover and mutation rates affect the convergence and stability. GA is dependent on the gene coding method. It finds sub-optimal solution.

\subsection{Ant colony optimisation}

ACO is based on foraging behaviour of the ants. Ants use pheromone as chemical messengers, each ant lays a scent chemical for communicating each other. All the ants are able to follow the route marked by other. When an ant found food, it marks the place with chemical and makes a route. As more and more ants track the marked route, this path becomes favoured. According to See and Wong (2008) ACO has emerged as potent meta-heuristic procedure to solve FLP. DFLP with unequal-sized facilities solved effectively by Corry and Kozan in 2004. Three different types of ACO approaches have been proposed by McKendall and Shang in 2006 to solve DFLP. ACO variant-based solution for layout problem of unequal area facilities has been considered by Komarudin and Wong (2010). Flexible bay structuring along with ACO has been used to optimise FLP by Kulturel-Konak and Konak (2011). An ACO for solving an industrial layout problem has been implemented by Hani et al. (2007). Many other researchers (Ramkumar et al., 2009b; Solimanpur et al., 2004; Teo and Ponnambalam, 2008) also focused on application of ACO in solving the facility layout problem. Marco et al. (2006) proposed different kinds of ACO algorithms such as; ant system (AS), ant colony system, elitist AS, ant-q, rank-based AS, best-worst AS, hyper-cube AS, and max-min AS. Corne et al. (1999) proposed AS to find the shortest path in the travelling salesman problem. If $m$ is the total number of ants in the problem then, according to Marco et al. (1996) at each iteration of the algorithm, each of the $m=\sum_{i=1}^{n} b_{i}(t)$, ants moves from the city $i$ at time $t$ to city $j$ at time $t+1$, where $b_{i}(t)$ denotes the number of artificial ants in city $i$ at time $t$. A cycle is the tour of each ant completed during $n$ iterations; its time interval is equal to $(t, t$ $+n), t_{a b u}$ is the tabu list of the cities already been visited, it is made to prevent revisiting. Equation (1) represents the trail intensity, in this equation coefficient $\rho$ stands for amount of trail after evaporation in the time interval $(t, t+n), \tau_{i j}(t)$ represents trail intensity on edge $(i, j)$ at time $t, \rho<1$, the initial trial intensity $\tau_{i j}(0)$ is a small positive number. $\Delta \tau_{i j}$ can be defined as equation (2) where, $\Delta \tau_{i j}^{k}$ denotes the trail value, which is deposited on for each unit of length of the edge $(i, j)$ by the ant $k$ in the time interval $(t, t$ $+n$ ). Equation (3) gives $\Delta \tau_{i j}^{k}$, where $L$ is the total tour distance, and $Q$ is constant. Equation (4) denotes the probability of ant $k$ moves from the current city $i$ to nearest city $j$ 
by using the edge $(i, j)$ with the highest trail intensity $\tau_{i j}(t)$ and visibility $\eta_{i j}=\frac{1}{d_{i j}}$, where $N$ is the set of cities and parameters $\alpha$ and $\beta$ indicate the significance of trail against visibility.

$$
\begin{aligned}
& \tau_{i j}(t+n)=\rho . \tau_{i j}(t)+\Delta \tau_{i j} \\
& \Delta \tau_{i j}=\sum_{k=1}^{m} \Delta \tau_{i j}^{k} \\
& \Delta \tau_{i j}^{k}= \begin{cases}\frac{Q}{L_{k}} & \text { if ant } k \text { uses edge }(i, j) \text { in its tour in the time interval }(t, t+n) \\
0 & \text { otherwise }\end{cases} \\
& P_{i j}^{k}(t)= \begin{cases}\frac{\left[\tau_{i j}(t)\right]^{\alpha}\left[\eta_{i j}\right]^{\beta}}{\sum_{k}\left[\tau_{i j}(t)\right]^{\alpha}\left[\eta_{i j}\right]^{\beta}} & \text { if } j, k \in\left\{N-\operatorname{tabu}_{k}\right\} \\
0 & \text { othervise }\end{cases}
\end{aligned}
$$

This algorithm is continual till the number of tour reaches to a user defined value (Moslemipour et al., 2012). This algorithm contains robustness, flexibility and scalability in changing environment. The parameters in ACO approach initialisations at random or by trial and errors basis. The coding is difficult as compare to other approaches.

\section{Single point-based search algorithm for facility layout}

\subsection{Simulated annealing}

Kirkpatrick et al. (1983) proposed SA algorithm by generalising the metropolis's approach and replacing the atom's energy with the cost function. SA is based on metal annealing processing; the main benefit of this algorithm is its capacity to keep away from being trapped in local optima. The search moves a piecewise path; with each move probability of acceptance is evaluated. In this way, it accepts the changes that improve the objective function and also keep changes that do not improve the objective. In the field of FLP, this approach is being preferred by researchers starting from manufacturing cell design to multi-objective layout planning (Ioannou, 2007; Şahin et al., 2010; Castillo and Peters, 2003; Dong et al., 2009; McKendall et al., 2006; Şahin and Türkbey, 2009; Souilah, 1995; Sugiyono, 2006; Matsuzaki et al., 1999). Ku et al. (2011) proposed a SAbased parallel GA approach for facility layout problem. Matai (2015) solved a multi-objective facility layout problem using modified SA. Kulturel-Konak and Konak (2015) presented a large-scale hybrid SA algorithm for cyclic facility layout problems. The problems of dynamic facility layout with equal-sized facilities have been solved by Baykasoğlu and Gindy (2001). DFLP also solved with multi-start SA by Ashtiani et al. (2007). DFLP with budget constraint is handled successfully by Şahin et al. (2010). Other researchers like Mir and Imam (2001), Singh and Sharma (2008), Yang et al. (2005), and Şahin et al. (2010) also implemented SA as an optimisation tool for layout planning. 
Suman and Kumar (2006), presented a survey on SA, this survey was based on single and multi-objective optimisation.

SA start with a randomly generated initial solution $s^{0}$. The algorithm has two loops, inner loop and the outer loop. At each iteration of the inner loop, a solution, $s^{\prime}$ is generated by the local search technique, in the neighbouring area of the best current solution, $s$. The solution $s^{\prime}$ is evaluated by the objective function $f$. If $f\left(s^{\prime}\right) \leq f(s)$ then it is accepted as a current best solution. In case of $f\left(s^{\prime}\right)>f(s)$ it is also accepted if $x \in(0,1) \leq$ $P$, where $x$ is randomly generated number and $P=\exp \left(\left(f(s)-f\left(s^{\prime}\right)\right) / T_{e l}\right.$ is the probability of accepting this non-improving neighbouring solution $s$.

The outer loop starts with a high a high value of a control parameter, i.e., temperature and at each iteration of this loop or at each temperature, the inner loop must be repeated until the system reaches the steady state. $\mathrm{P}$ is high at the initial stages of the algorithm $\left(P_{i n} \approx 1\right)$ and at the final stage it approach s to a very small value $(P f \approx 0)$. In the iteration $e l$, current value of the temperature $\left(T_{e l}\right)$ of the outer loop is calculated as $T_{e l}=T_{0} \alpha^{e l}(e l=$ $\left.0,1,2, \ldots e l_{\max }\right)$, where $\alpha \in(0.80,0.99)$ is the cooling ratio, $e l_{\max }$ denotes the maximum number of the iterations of the outer loop, and $\mathrm{T}_{0}$ denotes the initial value of the temperature, it can be calculated as $T_{0}=-0.1 f\left(s^{0}\right) / \ln (0.25)$ (Moslemipour et al., 2012). It is free of local optima. The computational time is low. SA is easy for implementation and convergent properties. The quality of solution is depends on the initial temperature and on the maximum iteration number of the inner loop.

\subsection{Tabu search}

Glover (1989) proposed the TS; this technique uses memory and search history as a major component of this method. Most of the available methods use the result of the last steps and these are memory less but TS is opposite to these. Due to the use of search history, TS has avoided revisiting recently tried local solutions and it saves a significant amount of computing time. TS is widely used in FLP for optimisation of material handling cost, minimisation of re-layout cost, utilisation of space, etc. (Abdinnour-Helm and Hadley, 2000; McKendall and Hakobyan, 2010; Seo et al., 2006; Scholz et al., 2009; Yang et al., 1999). An approach for handling DFLP has been presented by Kaku and Mazzola (1997). A large sized DFLP with 'un-equal size facility' solved by McKendall and Hakobyan (2010). Some other researchers also found the application of TS in solving the layout problem like Sugiyono (2006), Miao and Xu (2009), Kaku and Mazzola (1997), Chiang (2001) and Chang et al. (2009). Uncertainty in production volume and flexibility in the product routing is considered by Kulturel-Konak et al. (2004). TS heuristic for efficiency of DFLP has been proposed by Bozorgi et al. (2015). TS, GA, and SA are compared on different types of FLP by Arostegui et al. (2006). TS starts with an initial solution $s^{0}$ as the best current solution s (i.e., $s^{0}=s=s^{*}$ ). A new solution $s^{\prime}$ is produced at each iteration, during a local search process in the neighbourhood of the current solution s. if $s^{\prime}$ is better than $s$, then, it is considered as the best solution (i.e., $s^{\prime}=s$ $\left.=s^{*}\right)$. In order to find optimal solution, the very soon found solutions, which are taboo and forbidden to be visited, are stored in tabu list (Moslemipour et al., 2012). The oldest number from the list must be removed for keeping the size of the tabu list constant, and it will be continued till termination criterion is fulfilled. TS use flexible memory to retain the history. The output solution is not necessarily an optimal solution. 


\section{Other FLP algorithms}

There are some other approaches also have been applied for facility layout problems like an artificial immune system (AIS)-based algorithm to solve unequal area facility layout problem proposed by Haktanirlar Ulutas and Kulturel-Konak (2012). Scatter search (SS) algorithm for layout problem in flexible manufacturing systems suggested by Satheesh Kumar et al. (2008). This approach also implemented by Pantrigo et al. (2012). Kothari and Ghosh (2014b) suggested a SS algorithm for the single row facility layout problem. Saravanan and Arulkumar (2015) implemented artificial bee colony algorithm for design and optimise the fixed area layout problems. Ripon et al. (2013) proposed adaptive variable neighbourhood search for handling multi-objective facility layout problems with unequal area facilities. Wang and Tang (2011) presented an improved adaptive GA based on hormone modulation mechanism for job-shop scheduling problem of industries.

\subsection{Particle swarm optimisation}

Kennedy and Eberhard (1995) developed PSO based on swarm manners in nature. After then, this technique got lots of attention, and became the centre point of research in the field of intelligence of the swarm. PSO has been applied in various fields of research like design and scheduling problems, parameter optimisation of machine, etc. By adjusting the trajectories of individual particles, it searches the space for the objective function, and these particles trace a piecewise path which can be modelled in position vector. Particle updates its location to the new, when finds a location better than previously found and it will continue till particle finds a global best among all the current best solution after a certain number of iterations. Facility layout problem can also be solved with PSO. PSO has been applied in FLP by some researchers (Paul et al., 2006; Ohmori et al., 2010; Teo and Ponnambalam, 2008; Hardin and Usher, 2005; Durán et al., 2008; Reddy et al., 2012). Asl and Wong (2015) Solved unequal-area static and DFLPs by implementing modified PSO. According to Wang et al. (2008c) and Rezazadeh et al. (2009), in PSO, including $\mathrm{m}$ particles, equation (5) and equation (6) are used to update the position and velocity of the particle $i$ at iteration $t$ respectively. The dimensional vectors $X_{i}^{t}=\left(x_{i 1}^{t}, x_{i 2}^{t}, x_{i 3}^{t}, \ldots, x_{i d}^{t}\right)$ and $V_{i}^{t}=\left(v_{i 1}^{t}, v_{i 2}^{t}, \ldots, v_{i d}^{t}\right) \quad(i=1,2,3, \ldots, m)$ represents the position and flying velocity coordinates of the $i^{\text {th }}$ particle at iteration $t$. The position coordinates of particle $i$ associated with its pbest and gbest fitness values at iteration $t$ are also represented by $P_{i}^{t}=\left(p_{i 1}^{t}, p_{i 2}^{t}, p_{i 3}^{t}, \ldots p_{i d}^{t}\right)$, and $P_{g}^{t}=\left(p_{g 1}^{t}, p_{g 2}^{t}, \ldots, p_{g d}^{t}\right)$ respectively.

$$
\begin{aligned}
& v_{i}^{t}=\left(\omega v_{i}^{t-1}+c_{1} r_{1}\left(p_{i}^{t-1}-x_{i}^{t-1}\right)+c_{2} r_{2}\left(p_{g}^{t-1}-x_{i}^{t-1}\right)\right) \\
& x_{i}^{t}=x_{i}^{t-1}+v_{i}^{t-1}
\end{aligned}
$$

where

$t \quad$ iteration number

$\omega \quad$ inertia weight

$c_{1}, c_{2}$ are usually equal to 2 , are cognition learning factor and social learning factors respectively 
$r_{1}, r_{2}$ random numbers uniformly distributed in $[0,1]$.

According to Clerc and Kennedy (2002) in order to prevent the particle's velocities grow to infinity, the suitable values of $\omega, c_{1}$ and $c_{2}$ must be selected (Moslemipour et al., 2012).

\subsection{Hybrid algorithm}

Hybrid algorithms are made by the combination of various solution approaches. In facility layout problems, these algorithms play a very effective role in reaching an optimised solution. For solving the layout problem a combination of GA, SA and Hitchcock's method has been proposed by Mahdi et al. in 1998. SA, GA and TS, are combined in a single algorithm for handling fixed shape and unequal sized layout problem by Lee and Lee (2002). A GA-SA-based algorithm for layout design has been presented by Leno et al. (2015). A hybrid algorithm for optimising facility layout has been considered by Tasadduq et al. (2015). GA with SA is proposed by Huntley and Brown (1991) for obtaining a hybrid algorithm. A hybrid approach for handling the unequal sized facility layout is considered by Mir and Imam (2001), in their algorithm initial solution is generated by SA and for determining the optimal location of facilities analytical search is applied. The DFLP has been solved by Erel et al. (2003) using a three stage hybrid algorithm. Hasani et al. (2015) suggested a hybrid meta-heuristic for dynamic layout problems with transportation system design using variable neighbourhood search (VNS) and SA. Chen et al. (2015) combined improved adaptive GA with SS for layout problem in non-rectangular logistics parks with split lines. Hu et al. (2013) proposed a hybrid approach using the SS, improved adaptive genetic, and expectation maximisation algorithms for phase-type distribution fitting. A hybrid meta-heuristic algorithm has been suggested by Rodriguez et al. in 2006 for handling DFLP. Table 1 shows a list of meta-heuristic approaches used for handling facility layout problem.

Table 1 List of meta-heuristic approaches used for handling facility layout problem

\begin{tabular}{|c|c|c|c|c|c|c|c|}
\hline Reference & Year & $G A$ & $T S$ & $S A$ & $A C O$ & $P S O$ & Hybrid \\
\hline Souilah & 1995 & & & $\checkmark$ & & & \\
\hline Ashtiani et al. & 2007 & & & $\checkmark$ & & & \\
\hline Asl and Wong & 2015 & & & & & $\checkmark$ & \\
\hline Azadivar and Wang & 2000 & $\checkmark$ & & & & & \\
\hline Balakrishnan and Cheng & 2000 & $\checkmark$ & & & & & \\
\hline Balakrishnan et al. & 2003 & & & & & & $\checkmark$ \\
\hline Baykasoğlu and Gindy & 2001 & & & $\checkmark$ & & & \\
\hline Baykasoglu et al. & 2006 & & & & $\checkmark$ & & \\
\hline Castillo and Peters & 2003 & & & $\checkmark$ & & & \\
\hline Chang et al. & 2009 & & $\checkmark$ & & & & \\
\hline Chen and Lo & 2014 & & & & $\checkmark$ & & \\
\hline Chen and Rogers & 2009 & & & & $\checkmark$ & & \\
\hline Chiang & 2001 & & $\checkmark$ & & & & \\
\hline Chwif et al. & 1998 & & & $\checkmark$ & & & \\
\hline
\end{tabular}


Table 1 List of meta-heuristic approaches used for handling facility layout problem (continued)

\begin{tabular}{|c|c|c|c|c|c|c|c|}
\hline Reference & Year & $G A$ & $T S$ & $S A$ & $A C O$ & PSO & Hybrid \\
\hline Conway and Venkataramanan & 1994 & $\checkmark$ & & & & & \\
\hline Corry and Kozan & 2004 & & & & $\checkmark$ & & \\
\hline Dong et al. & 2009 & & & $\checkmark$ & & & \\
\hline Drezner & 2008 & & & & & & $\checkmark$ \\
\hline Dunker et al. & 2005 & & & & & & $\checkmark$ \\
\hline Durán et al. & 2008 & & & & & $\checkmark$ & \\
\hline Engelbrecht & 2005 & & & & & $\checkmark$ & \\
\hline Erel et al. & 2003 & & & & & & $\checkmark$ \\
\hline Ficko et al. & 2004 & $\checkmark$ & & & & & \\
\hline Gau and Meller & 1999 & $\checkmark$ & & & & & \\
\hline Hani et al. & 2007 & & & & $\checkmark$ & & \\
\hline Hardin and Usher & 2005 & & & & & $\checkmark$ & \\
\hline Abdinnour-Helm and Hadley & 2000 & & $\checkmark$ & & & & \\
\hline Hicks & 2004 & $\checkmark$ & & & & & \\
\hline Hu and Wang & 2004 & $\checkmark$ & & & & & \\
\hline Hu et al. & 2007 & $\checkmark$ & & & & & \\
\hline Huntley and Brown & 1991 & & & & & & $\checkmark$ \\
\hline Ioannou & 2007 & & & $\checkmark$ & & & \\
\hline Jayachitra and Prasad & 2010 & $\checkmark$ & & & & & \\
\hline Jeong et al. & 2009 & & & & & & $\checkmark$ \\
\hline Ji et al. & 2006 & & & & & & $\checkmark$ \\
\hline Kaku and Mazzola & 1997 & & $\checkmark$ & & & & \\
\hline Kia et al. & 2014 & $\checkmark$ & & & & & \\
\hline Kochhar and Heragu & 1999 & $\checkmark$ & & & & & \\
\hline Komarudin and Wong & 2010 & & & & $\checkmark$ & & \\
\hline Kulturel-Konak and Konak & 2011 & & & & $\checkmark$ & & \\
\hline Kothari and Ghosh & $2014 a$ & $\checkmark$ & & & & & \\
\hline Krishnan et al. & 2008 & $\checkmark$ & & & & & \\
\hline Krishnan et al. & 2009 & $\checkmark$ & & & & & \\
\hline $\mathrm{Ku}$ et al. & 2011 & & & $\checkmark$ & & & \\
\hline Kulkarni and Shanker & 2007 & $\checkmark$ & & & & & \\
\hline Kulturel-Konak et al. & 2004 & & $\checkmark$ & & & & \\
\hline Lee and Lee & 2002 & & & & & & $\checkmark$ \\
\hline Li et al. & 2009 & & & & & & $\checkmark$ \\
\hline Liang and Chao & 2008 & & $\checkmark$ & & & & \\
\hline Liu and Abraham & 2007 & & & & & & $\checkmark$ \\
\hline Liu and $\mathrm{Li}$ & 2006 & $\checkmark$ & & & & & \\
\hline Longo et al. & 2005 & $\checkmark$ & & & & & \\
\hline
\end{tabular}


Table 1 List of meta-heuristic approaches used for handling facility layout problem (continued)

\begin{tabular}{|c|c|c|c|c|c|c|c|}
\hline Reference & Year & $G A$ & $T S$ & $S A$ & $A C O$ & PSO & Hybrid \\
\hline Mahdi et al. & 1998 & & & & & & $\checkmark$ \\
\hline Arostegui et al. & 2006 & & $\checkmark$ & & & & \\
\hline Matai & 2015 & & & $\checkmark$ & & & \\
\hline Matsuzaki et al. & 1999 & & & $\checkmark$ & & & \\
\hline McKendall & 2008 & & $\checkmark$ & & & & \\
\hline McKendall and Hakobyan & 2010 & & $\checkmark$ & & & & \\
\hline McKendall and Shang & 2006 & & & & $\checkmark$ & & \\
\hline McKendall et al. & 2006 & & & $\checkmark$ & & & \\
\hline Miao and $\mathrm{Xu}$ & 2009 & & & & & & $\checkmark$ \\
\hline Mir and Imam & 2001 & & & & & & $\checkmark$ \\
\hline Ning et al. & 2010 & & & & $\checkmark$ & & \\
\hline Ohmori et al. & 2010 & & & & & $\checkmark$ & \\
\hline Osman et al. & 2003 & $\checkmark$ & & & & & \\
\hline Paul et al. & 2006 & & & & & $\checkmark$ & \\
\hline See and Wong & 2008 & & & & $\checkmark$ & & \\
\hline Poli et al. & 2007 & & & & & $\checkmark$ & \\
\hline Rajasekharan et al. & 1998 & $\checkmark$ & & & & & \\
\hline Ramkumar and Ponnambalam & 2006 & & & & & & $\checkmark$ \\
\hline Ramkumar et al. & $2009 b$ & & & & $\checkmark$ & & \\
\hline Ramkumar et al. & $2009 a$ & $\checkmark$ & & & & & \\
\hline Reddy et al. & 2012 & & & & & $\checkmark$ & \\
\hline Rezazadeh et al. & 2009 & & & & & $\checkmark$ & \\
\hline Rodriguez et al. & 2006 & & & & & & $\checkmark$ \\
\hline Şahin and Türkbey & 2009 & & & $\checkmark$ & & & \\
\hline Şahin et al. & 2010 & & & $\checkmark$ & & & \\
\hline Samarghandi and Eshghi & 2010 & & $\checkmark$ & & & & \\
\hline Samarghandi and Jahantigh & 2011 & & & & & $\checkmark$ & \\
\hline Scholz et al. & 2009 & & $\checkmark$ & & & & \\
\hline See and Wong & 2008 & & & & $\checkmark$ & & \\
\hline Seo et al. & 2006 & & $\checkmark$ & & & & \\
\hline Singh and Sharma & 2008 & & & $\checkmark$ & & & \\
\hline Sirirat and Peerayuth & 2007 & & & & & & $\checkmark$ \\
\hline Smith and Norman & 2000 & $\checkmark$ & & & & & \\
\hline Solimanpur et al. & 2004 & & & & $\checkmark$ & & \\
\hline Solimanpur et al. & 2010 & & & & $\checkmark$ & & \\
\hline Souilah & 1995 & & & $\checkmark$ & & & \\
\hline Sugiyono & 2006 & & $\checkmark$ & & & & \\
\hline Suman and Kumar & 2006 & & & $\checkmark$ & & & \\
\hline
\end{tabular}


Table 1 List of meta-heuristic approaches used for handling facility layout problem (continued)

\begin{tabular}{|c|c|c|c|c|c|c|c|}
\hline Reference & Year & $G A$ & $T S$ & $S A$ & $A C O$ & PSO & Hybrid \\
\hline Surya & 2009 & & $\checkmark$ & & & & \\
\hline Teo and Ponnambalam & 2008 & & & & & & $\checkmark$ \\
\hline Thangavel et al. & 2006 & & & & $\checkmark$ & & \\
\hline Tuzkaya et al. & 2013 & & & & & & $\checkmark$ \\
\hline Wang et al. & $2008 b$ & $\checkmark$ & & & & & \\
\hline Wang et al. & $2008 \mathrm{a}$ & $\checkmark$ & & & & & \\
\hline Wu and Appleton & 2002 & $\checkmark$ & & & & & \\
\hline $\mathrm{Wu}$ and $\mathrm{Ji}$ & 2008 & $\checkmark$ & & & & & \\
\hline Wu et al. & 2007 & $\checkmark$ & & & & & \\
\hline Yang et al. & 1999 & & $\checkmark$ & & & & \\
\hline Yang et al. & 2005 & & & $\checkmark$ & & & \\
\hline Zhang et al. & 2014 & $\checkmark$ & & & & & \\
\hline
\end{tabular}

\section{Future perception of meta-heuristic for FLP}

Importance of meta-heuristic optimisation in the field of facility layout planning in today's dynamic environment can be easily observed from the above discussion. Maximum researchers have been attempted PSO, GA, ACO, SA, TS, and hybrid algorithms for DFLP optimisation. These algorithms have various advantages and disadvantages; GA has ability to solve different kinds of combinatorial optimisation problems. The coding in ACO is difficult as compare to other approaches. The computational time for SA is low. ACO works on principle of minimisation behaviour, so it can be considered as the most suitable for the facility layout problems with a goal to minimise the material handling cost. But still this algorithm is in its improvement phase. Results of SA as optimisation tool are considerable, if we compare the utilisation of this approach with ACO and PSO; it is applied by a huge number of researchers. TS widely used in layout planning for optimisation of material handling cost, utilisation of space, minimisation of re-layout cost, etc. The GA applied in most of the research, it is the oldest technique and still in the eyes of researchers. PSO has been utilised by very few researchers; the outcomes of the implementation of this approach are appreciable. From the present study authors analysed the '\% utilisation' of different meta-heuristic approach during different time span (such as; 'before 2000', '2000-2004', '2005-2009', '2010$\left.2015^{\prime}\right)$. It is crystal clear from this analysis that, GA and SA widely used by most of the researchers, on the other hand PSO and ACO did not utilised by any of the researchers. For the span of 'before 2000', GA and SA have been utilised by more researchers $(33 \%)$. TS and hybrid algorithms were used by $17 \%$ of the researchers whereas the utilisation of ACO and PSO were almost negligible. In the next time span '2000-2004', the \% utilisation of GA was $41 \%$ which was also the highest for this particular approach among different considered time spans. Hybrid approaches were utilised by $23 \%$ researchers. TS and SA were considered by $13 \%$ and $14 \%$ researchers respectively however, this $\%$ utilisation of these approaches were decreased from period 'before 2000'. ACO and PSO 
were at their initial level of being utilised by different researchers. For the span of '20052009', almost all the approaches were equally utilised and the \% utilisation was varying from 11-21\%. But, in '2010-2015' time span, ACO utilisation was at its boom (46\%). PSO was also utilised by $15 \%$ researchers and GA was declined to $8 \%$ which was $41 \%$ in '2000-2004'. Figure 2 and 3 demonstrates the research output in the form of graph and chart form which further supports the above discussed data. If a comparison made on overall percent utilisation (Figure 4), author observed from the analysis GA used by most of the researches (25\%) and PSO least utilisation (8\%). Hybrid approaches (19\%) stands in second place, these overcomes the weakness of some other solution approaches, by using the strength of some other technique. The present research output reveals that the older approaches i.e., GA and SA declined from past to present and it is further predicted that the improvement chances of these methods in next future are very lesser. On the other hand, approaches i.e., ACO and PSO are at their increasing phase at are predicted to be at higher in future. Some approaches were at their constant level of utilisation i.e., hybrid and TS and in near period it is also predicted that these methods will be highly utilised. The outcome of the present study will help the industrial layout designers to take decision regarding the selection of appropriate approach for layout problems. One approach never been best for all the similar kind of problems and also not best suited in all environmental conditions.

Figure $2 \%$ utilisation vs. time period for different approaches (see online version for colours)

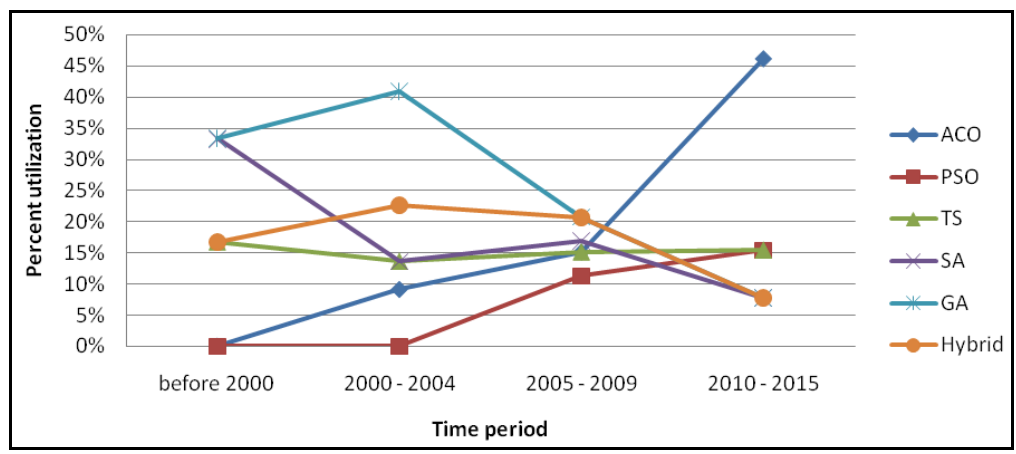

Figure 3 Comparison of percent utilisation for different approach in different time span (see online version for colours)

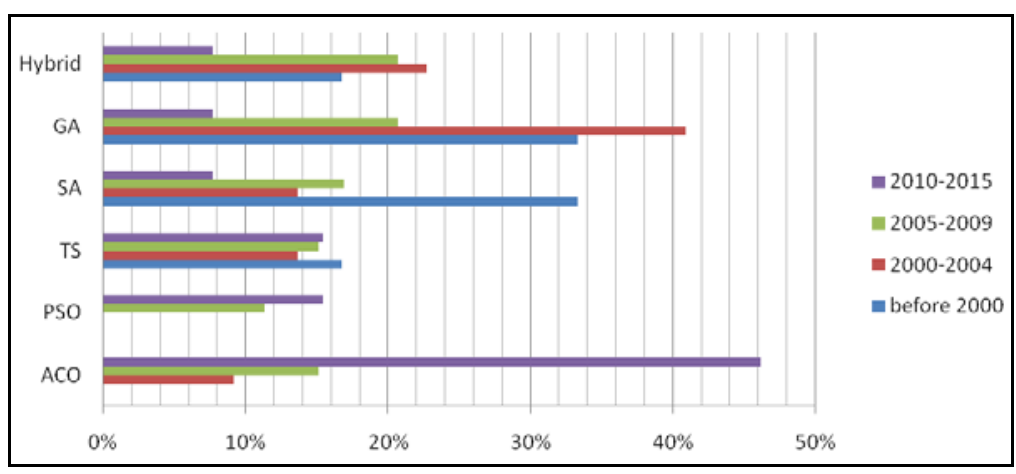


Figure $4 \%$ utilisation of different meta-heuristic for FLP (see online version for colours)

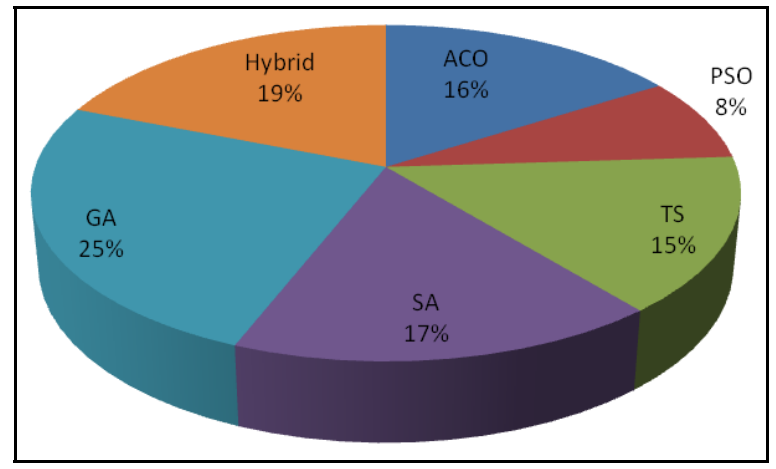

\section{Conclusions}

In the present study, various meta-heuristic approaches used in the FLP are discussed briefly. Research papers based on these approaches have been categorised. The meta-heuristic approaches are classified based on their search algorithm (single point search and population-based search). From the literature, authors observed that PSO, GA, TS, and ACO are mostly used by researchers for layout planning. Comparison based on percent utilisation also has been presented in the form of figure and table which reveals that the percentage utilisation are as: GA $(25 \%)>$ Hybrid approaches $(19 \%)>$ SA $(17 \%)$ $>\operatorname{ACO}(16 \%)>\operatorname{TS}(15 \%)>$ PSO $(8 \%)$. In the present study, \% utilisation of these algorithms has been also analysed for different time span, in the period of 'before 2000' GA and SA were used by most of researchers, and also GA was at its best in span '2000-2004'. During '2005-2009', all the considered approaches were utilised equally. But in '2010-2015', ACO was at its highest utilisation. The prediction of the future study for these considered approaches has also been made.

\section{References}

Abdinnour-Helm, S. and Hadley, S.W. (2000) 'Tabu search based heuristics for multi-floor facility layout', International Journal of Production Research, Vol. 38, No. 2, pp.365-383.

Arostegui, M.A., Kadipasaoglu, S.N. and Khumawala, B.M. (2006) 'An empirical comparison of tabu search, simulated annealing, and genetic algorithms for facilities location problems', International Journal of Production Economics, Vol. 103, No. 2, pp.742-754.

Ashtiani, B., Aryanezhad, M.B. and Moghaddam, B.F. (2007) 'Multi-start simulated annealing for dynamic plant layout problem', Journal of Industrial Engineering International, Vol. 3, No. 4, pp.44-50.

Asl, A.D. and Wong, K.Y. (2015 accepted) 'Solving unequal-area static and dynamic facility layout problems using modified particle swarm optimization', Journal of Intelligent Manufacturing, pp.1-20.

Azadivar, F. and Wang, J. (2000) 'Facility layout optimization using simulation and genetic algorithms', International Journal of Production Research, Vol. 38, No. 17, pp.4369-4383.

Balakrishnan, J. and Cheng, C.H. (1998) 'Dynamic layout algorithms: a state of the art survey', Omega, Vol. 26, No. 4, pp.507-521. 
Balakrishnan, J. and Cheng, C.H. (2000) 'Genetic search and the dynamic layout problem', Computers \& Operations Research, Vol. 27, No. 6, pp.587-593.

Balakrishnan, J., Cheng, C.H., Conway, D.G. and Lau, C.M. (2003) 'A hybrid genetic algorithm for the dynamic plant layout problem', International Journal of Production Economics, Vol. 86, No. 2, pp.107-120.

Baykasoğlu, A. and Gindy, N.N. (2001) 'A simulated annealing algorithm for dynamic layout problem', Computers \& Operations Research, Vol. 28, No. 14, pp.1403-1426.

Baykasoglu, A., Dereli, T. and Sabuncu, I. (2006) 'An ant colony algorithm for solving budget constrained and unconstrained dynamic facility layout problems', Omega, Vol. 34, No. 4, pp.385-396.

Bozorgi, N., Abedzadeh, M. and Zeinali, M. (2015) 'Tabu search heuristic for efficiency of dynamic facility layout problem', The International Journal of Advanced Manufacturing Technology, Vol. 77, Nos. 1-4, pp.689-703.

Caputo, A.C., Pelagagge, P.M., Palumbo, M. and Salini, P. (2015) 'Safety-based process plant layout using genetic algorithm', Journal of Loss Prevention in the Process Industries, Vol. 34, No. 1, pp.139-150.

Castillo, I. and Peters, B.A. (2003) 'An extended distance-based facility layout problem', International Journal of Production Research, Vol. 41, No. 11, pp.2451-2479.

Chang, C.C., Wu, T.H. and Chung, S. H. (2009) 'A novel approach for cell formation and cell layout design in cellular manufacturing system', International Conference on Management and Service Science, 2009. MASS'09, IEEE, September, pp.1-4.

Chen, G. and Rogers, J. (2009) 'Managing dynamic facility layout with multiple objectives', Portland International Conference on Management of Engineering \& Technology, 2009. PICMET 2009, IEEE, August, pp.1175-1184.

Chen, G.Y.H. and Lo, J.C. (2014) 'Dynamic facility layout with multi-objectives', Asia-Pacific Journal of Operational Research, Vol. 31, No. 4, p.1450027.

Chen, Y., Jiang, Y., Wahab, M.I.M. and Long, X. (2015) 'The facility layout problem in non-rectangular logistics parks with split lines', Expert Systems with Applications, Vol. 42, No. 21, pp.7768-7780.

Chiang, W.C. (2001) 'Visual facility layout design system', International Journal of Production Research, Vol. 39, No. 9, pp.1811-1836.

Chwif, L., Barretto, M.R.P. and Moscato, L.A. (1998) 'A solution to the facility layout problem using simulated annealing', Computers in Industry, Vol. 36, No. 1, pp.125-132.

Clerc, M. and Kennedy, J. (2002) 'The particle swarm-explosion, stability, and convergence in a multidimensional complex space', IEEE Transactions on Evolutionary Computation, Vol. 6, No. 1, pp.58-73.

Conway, D.G. and Venkataramanan, M.A. (1994) 'Genetic search and the dynamic facility layout problem', Computers \& Operations Research, Vol. 21, No. 8, pp.955-960.

Corne, D., Dorigo, M. and Glover, F. (1999) The Ant Colony Optimization Meta-Heuristic, New Ideas in Optimization, McGraw-Hill, London.

Corry, P. and Kozan, E. (2004) 'Ant colony optimisation for machine layout problems', Computational Optimization and Applications, Vol. 28, No. 3, pp.287-310.

de Alvarenga, A.G. and Negreiros-Gomes, F.J. (2000) 'Metaheuristic methods for a class of the facility layout problem', Journal of Intelligent Manufacturing, Vol. 11, No. 4, pp.421-430.

Delmaire, H., Langevin, A. and Riopel, D. (1997) 'Skeleton-based facility layout design using genetic algorithms', Annals of Operations Research, Vol. 69, No. 1, pp.85-104.

Dong, M., Wu, C. and Hou, F. (2009) 'Shortest path based simulated annealing algorithm for dynamic facility layout problem under dynamic business environment', Expert Systems with Applications, Vol. 36, No. 8, pp.11221-11232. 
Drezner, Z. (2008) 'Extensive experiments with hybrid genetic algorithms for the solution of the quadratic assignment problem', Computers \& Operations Research, Vol. 35, No. 3, pp.717-736.

Drira, A., Pierreval, H. and Hajri-Gabouj, S. (2007) 'Facility layout problems: a survey', Annual Reviews in Control, Vol. 31, No. 2, pp.255-267.

Dunker, T., Radons, G. and Westkamper, E. (2005) 'Combining evolutionary computation and dynamic programming for solving a dynamic facility layout problem', European Journal of Operational Research, Vol. 165, No. 1, pp.55-69.

Durán, O., Rodriguez, N. and Consalter, L.A. (2008) 'A PSO-based clustering algorithm for manufacturing cell design', Proceedings of the 1st International Conference on Forensic Applications and Techniques in Telecommunications, Information, and Multimedia and Workshop, Institute for Computer Sciences, Social-Informatics and Telecommunications Engineering (ICST), January, p.53.

Eklund, N.H., Embrechts, M.J. and Goetschalckx, M. (2006) 'Efficient chromosome encoding and problem-specific mutation methods for the flexible bay facility layout problem', IEEE Transactions on Systems, Man, and Cybernetics, Part C: Applications and Reviews, Vol. 36, No. 4, pp.495-502.

Emami, S. and Nookabadi, A.S. (2013) 'Managing a new multi-objective model for the dynamic facility layout problem', The International Journal of Advanced Manufacturing Technology, Vol. 68, Nos. 9-12, pp.2215-2228.

Engelbrecht, A.P. (2005) Fundamentals of Computational Swarm Intelligence, John Wiley \& Sons, Chichester.

Erel, E., Ghosh, J.B. and Simon, J.T. (2003) 'New heuristic for the dynamic layout problem', Journal of the Operational Research Society, Vol. 54, No. 12, pp.1275-1282.

Ficko, M., Brezocnik, M. and Balic, J. (2004) 'Designing the layout of single-and multiple-rows flexible manufacturing system by genetic algorithms', Journal of Materials Processing Technology, Vol. 157, No. 4, pp.150-158.

Gau, K.Y. and Meller, R.D. (1999) 'An iterative facility layout algorithm', International Journal of Production Research, Vol. 37, No. 16, pp.3739-3758.

Glover, F. (1989) 'Tabu search-part I', ORSA Journal on Computing, Vol. 1, No. 3, pp.190-206.

Gonçalves, J.F. and Resende, M.G. (2015) 'A biased random-key genetic algorithm for the unequal area facility layout problem', European Journal of Operational Research, Vol. 246, No. 1, pp.86-107.

Haktanirlar Ulutas, B. and Kulturel-Konak, S. (2012) 'An artificial immune system based algorithm to solve unequal area facility layout problem', Expert Systems with Applications, Vol. 39, No. 5, pp.5384-5395.

Hani, Y., Amodeo, L., Yalaoui, F. and Chen, H. (2007) 'Ant colony optimization for solving an industrial layout problem', European Journal of Operational Research, Vol. 183, No. 2, pp.633-642.

Hardin, C.T. and Usher, J.S. (2005) 'Facility layout using swarm intelligence', Swarm Intelligence Symposium, 2005. SIS 2005. Proceedings, June, IEEE, pp.424-427.

Hasani, A., Soltani, R. and Eskandarpour, M. (2015) 'A hybrid meta-heuristic for the dynamic layout problem with transportation system design', International Journal of EngineeringTransactions B: Applications, Vol. 28, No. 8, p.1175.

Hicks, C. (2004) 'A genetic algorithm tool for designing manufacturing facilities in the capital goods industry', International Journal of Production Economics, Vol. 90, No. 2, pp.199-211.

Holland, J.H. (1992) Adaptation in Natural and Artificial Systems: An Introductory Analysis with Applications to Biology, Control, and Artificial Intelligence, MIT Press, Cambridge.

Hu, G.H., Chen, Y.P., Zhou, Z.D. and Fang, H.C. (2007) 'A genetic algorithm for the inter-cell layout and material handling system design', The International Journal of Advanced Manufacturing Technology, Vol. 34, Nos. 11-12, pp.1153-1163. 
Hu, L., Jiang, Y., Zhu, J. and Chen, Y. (2013) 'Hybrid of the scatter search, improved adaptive genetic, and expectation maximization algorithms for phase-type distribution fitting', Applied Mathematics and Computation, Vol. 219, No. 10, pp.5495-5515.

Hu, M.H. and Wang, M.J. (2004) 'Using genetic algorithms on facilities layout problems', The International Journal of Advanced Manufacturing Technology, Vol. 23, Nos. 3-4, pp.301-310.

Huntley, C.L. and Brown, D.E. (1991) 'A parallel heuristic for quadratic assignment problems', Computers \& Operations Research, Vol. 18, No. 3, pp.275-289.

Ioannou, G. (2007) 'An integrated model and a decomposition-based approach for concurrent layout and material handling system design', Computers \& Industrial Engineering, Vol. 52, No. 4, pp.459-485.

Jajodia, S., Minis, I., Harhalakis, G. and Proth, J.M. (1992) 'CLASS: computerized layout solutions using simulated annealing', International Journal of Production Research, Vol. 30, No. 1, pp.95-108.

Jayachitra, R. and Prasad, P.S.S. (2010) 'Design and selection of facility layout using simulation and design of experiments', Indian Journal of Science and Technology, Vol. 3, No. 4, pp.437-446.

Jeong, S.J., Kim, K.S. and Lee, Y.H. (2009) 'The efficient search method of simulated annealing using fuzzy logic controller', Expert Systems with Applications, Vol. 36, No. 3, pp.7099-7103.

Ji, P., Wu, Y. and Liu, H. (2006) 'A solution method for the quadratic assignment problem (QAP)', The Sixth International Symposium on Operations Research and Its Applications (ISORA'06), August, pp.106-117.

Kaku, B.K. and Mazzola, J.B. (1997) 'A tabu-search heuristic for the dynamic plant layout problem', INFORMS Journal on Computing, Vol. 9, No. 4, pp.374-384.

Kennedy, J. and Eberhart, R.C. (1995) 'Particle swarm optimization', Proceedings of the IEEE International Conference on Neural Networks, pp.1942-1948.

Kheirkhah, A., Navidi, H. and Messi Bidgoli, M. (2015) 'Dynamic facility layout problem: a new bilevel formulation and some metaheuristic solution methods', IEEE Transactions on Engineering Management, Vol. 62, No. 3, pp.396-410.

Kia, R., Khaksar-Haghani, F., Javadian, N. and Tavakkoli-Moghaddam, R. (2014) 'Solving a multi-floor layout design model of a dynamic cellular manufacturing system by an efficient genetic algorithm', Journal of Manufacturing Systems, Vol. 33, No. 1, pp.218-232.

Kirkpatrick, F., Gelatt, C. and Vecci, M. (1983) 'Optimization by simulated annealing', Science Magazine, Vol. 220, No. 4598, pp.671-680.

Kochhar, J. and Heragu, S.S. (1999) 'Facility layout design in a changing environment', International Journal of Production Research, Vol. 37, No. 11, pp.2429-2446.

Komarudin and Wong, K.Y. (2010) 'Applying ant system for solving unequal area facility layout problems', European Journal of Operational Research, Vol. 202, No. 3, pp.730-746.

Kothari, R. and Ghosh, D. (2014a) 'An efficient genetic algorithm for single row facility layout', Optimization Letters, Vol. 8, No. 2, pp.679-690.

Kothari, R. and Ghosh, D. (2014b) 'A scatter search algorithm for the single row facility layout problem', Journal of Heuristics, Vol. 20, No. 2, pp.125-142.

Krishnan, K.K., Cheraghi, S.H. and Nayak, C.N. (2008) 'Facility layout design for multiple production scenarios in a dynamic environment', International Journal of Industrial and Systems Engineering, Vol. 3, No. 2, pp.105-133.

Krishnan, K.K., Jaafari, A.A., Sanpour, M.A. and Hojabri, H. (2009) 'A mixed integer programming formulation for multifloor layout', African Journal of Business Management, Vol. 3, No. 10, pp.616-620.

$\mathrm{Ku}, \mathrm{M} . Y ., \mathrm{Hu}, \mathrm{M} . \mathrm{H}$. and Wang, M.J. (2011) 'Simulated annealing based parallel genetic algorithm for facility layout problem', International Journal of Production Research, Vol. 49, No. 6, pp.1801-1812. 
Kulkarni, P.C. and Shanker, K. (2007) 'A genetic algorithm for layout problems in cellular manufacturing systems', IEEE International Conference on Industrial Engineering and Engineering Management, IEEE, December, pp.694-698.

Kulturel-Konak, S. and Konak, A. (2011) 'Unequal area flexible bay facility layout using ant colony optimisation', International Journal of Production Research, Vol. 49, No. 7, pp.1877-1902.

Kulturel-Konak, S. and Konak, A. (2015) 'A large-scale hybrid simulated annealing algorithm for cyclic facility layout problems', Engineering Optimization, Vol. 47, No. 7, pp.963-978.

Kulturel-Konak, S., Smith, A.E. and Norman, B.A. (2004) 'Layout optimization considering production uncertainty and routing flexibility', International Journal of Production Research, Vol. 42, No. 21, pp.4475-4493.

Kundu, A. and Dan, P.K. (2012) 'Metaheuristic in facility layout problems: current trend and future direction', International Journal of Industrial and Systems Engineering, Vol. 10, No. 2, pp.238-253.

Lee, Y.H. and Lee, M.H. (2002) 'A shape-based block layout approach to facility layout problems using hybrid genetic algorithm', Computers \& Industrial Engineering, Vol. 42, No. 2, pp.237-248.

Leno, I.J., Sankar, S.S. and Ponnambalam, S.G. (2015 accepted) 'MIP model and elitist strategy hybrid GA - SA algorithm for layout design', Journal of Intelligent Manufacturing, pp.1-19.

Li, Y., Wen, Q., Li, L. and Peng, H. (2009) 'Hybrid chaotic ant swarm optimization', Chaos, Solitons \& Fractals, Vol. 42, No. 2, pp.880-889.

Liang, L.Y. and Chao, W.C. (2008) 'The strategies of tabu search technique for facility layout optimization', Automation in Construction, Vol. 17, No. 6, pp.657-669.

Liu, H. and Abraham, A. (2007) 'An hybrid fuzzy variable neighborhood particle swarm optimization algorithm for solving quadratic assignment problem', Journal of Universal Computer Science, Vol. 13, No. 7, pp.1032-1054.

Liu, X. and Li, X. (2006) 'An improved genetic algorithms-based approach on supply chainoriented facility layout scheduling system', WCICA 2006. The Sixth World Congress on Intelligent Control and Automation, 2006, IEEE, June, Vol. 1, pp.3081-3084.

Longo, F., Mirabelli, G. and Papoff, E. (2005) 'Material flow analysis and plant lay-out optimization of a manufacturing system', Intelligent Data Acquisition and Advanced Computing Systems: Technology and Applications, 2005. IDAACS 2005, IEEE, September, pp.727-731.

Mahdi, A.H., Amet, H. and Portman, M.C. (1998) Physical Layout with Minimization of the Transport Cost, Research Internal Report, LORIA, Nancy.

Marco, D., Mauro, B. and Thomas, S.U. (2006) 'Ant colony optimization: artificial ants as a computational intelligence technique', IEEE Computational Intelligence Magazine, Vol. 1, No. 1, pp.28-39.

Marco, D., Vittorio, M. and Alberto, C. (1996) 'The ant system: optimization by a colony of cooperating agents', IEEE Transactions on Systems, Man, and Cybernetics, Part B, Vol. 26, No. 1, pp.1-13.

Matai, R. (2015) 'Solving multi objective facility layout problem by modified simulated annealing', Applied Mathematics and Computation, Vol. 261, No. 1, pp.302-311.

Matsuzaki, K., Irohara, T. and Yoshimoto, K. (1999) 'Heuristic algorithm to solve the multi-floor layout problem with the consideration of elevator utilization', Computers \& Industrial Engineering, Vol. 36, No. 2, pp.487-502.

Mavridou, T.D. and Pardalos, P.M. (1997) 'Simulated annealing and genetic algorithms for the facility layout problem: a survey’, Computational Optimization and Applications, Vol. 7, No. 1, pp.111-126.

McKendall, A.R. and Hakobyan, A. (2010) 'Heuristics for the dynamic facility layout problem with unequal-area departments', European Journal of Operational Research, Vol. 201, No. 1, pp.171-182. 
McKendall, A.R. and Shang, J. (2006) 'Hybrid ant systems for the dynamic facility layout problem', Computers \& Operations Research, Vol. 33, No. 3, pp.790-803.

McKendall, A.R., Shang, J. and Kuppusamy, S. (2006) 'Simulated annealing heuristics for the dynamic facility layout problem', Computers \& Operations Research, Vol. 33, No. 8, pp.2431-2444.

McKendall, J.A.R. (2008) 'Improved tabu search heuristics for the dynamic space allocation problem', Computers \& Operations Research, Vol. 35, No. 10, pp.3347-3359.

Miao, Z. and Xu, K.L. (2009) 'Research of multi-rows facility layout based on hybrid algorithm', International Conference on Information Management, Innovation Management and Industrial Engineering, 2009, IEEE, December, Vol. 2, pp.553-556.

Mir, M. and Imam, M.H. (2001) 'A hybrid optimization approach for layout design of unequal-area facilities', Computers \& Industrial Engineering, Vol. 39, No. 1, pp.49-63.

Moslemipour, G., Lee, T.S. and Rilling, D. (2012) 'A review of intelligent approaches for designing dynamic and robust layouts in flexible manufacturing systems', The International Journal of Advanced Manufacturing Technology, Vol. 60, Nos. 1-4, pp.11-27.

Ning, X., Lam, K.C. and Lam, M.C.K. (2010) 'Dynamic construction site layout planning using max-min ant system', Automation in Construction, Vol. 19, No. 1, pp.55-65.

Ohmori, S., Yoshimoto, K. and Ogawa, K. (2010) 'Solving facility layout problem via particle swarm optimization', Third International Joint Conference on Computational Science and Optimization (CSO), 2010, IEEE, May, Vol. 1, pp.409-413.

Osman, H.M., Georgy, M.E. and Ibrahim, M.E. (2003) 'A hybrid CAD-based construction site layout planning system using genetic algorithms', Automation in Construction, Vol. 12, No. 6 , pp.749-764.

Ou-Yang, C. and Utamima, A. (2013) 'Hybrid estimation of distribution algorithm for solving single row facility layout problem', Computers \& Industrial Engineering, Vol. 66, No. 1, pp.95-103.

Pantrigo, J.J., Martí, R., Duarte, A. and Pardo, E.G. (2012) 'Scatter search for the cut width minimization problem', Annals of Operations Research, Vol. 199, No. 1, pp.285-304.

Paul, R.C., Asokan, P. and Prabhakar, V.I. (2006) 'A solution to the facility layout problem having passages and inner structure walls using particle swarm optimization', The International Journal of Advanced Manufacturing Technology, Vol. 29, Nos. 7-8, pp.766-771.

Phanden, R.K., Jain, A. and Verma, R. (2012a) 'A genetic algorithm-based approach for job shop scheduling', Journal of Manufacturing Technology Management, Vol. 23, No. 7, pp.937-946.

Phanden, R.K., Jain, A. and Verma, R. (2012b) 'A genetic algorithm-based approach for flexible job shop scheduling', Applied Mechanics and Materials, Vol. 110, No. 1, pp.3930-3937.

Pierreval, H., Caux, C., Paris, J.L. and Viguier, F. (2003) 'Evolutionary approaches to the design and organization of manufacturing systems', Computers \& Industrial Engineering, Vol. 44, No. 3, pp.339-364.

Poli, R., Kennedy, J. and Blackwell, T. (2007) 'Particle swarm optimization - an overview', Swarm Intelligence, Vol. 1, No. 1, pp.33-57.

Pourvaziri, H. and Naderi, B. (2014) 'A hybrid multi-population genetic algorithm for the dynamic facility layout problem', Applied Soft Computing, Vol. 24, No. 4, pp.457-469.

Rajasekharan, M., Peters, B.A. and Yang, T. (1998) 'A genetic algorithm for facility layout design in flexible manufacturing systems', International Journal of Production Research, Vol. 36, No. 1, pp.95-110.

Ramkumar, A.S. and Ponnambalam, S.G. (2006) 'Hybrid ant colony system for solving quadratic assignment formulation of machine layout problems', IEEE Conference on Cybernetics and Intelligent Systems, 2006, IEEE, June, pp.1-5.

Ramkumar, A.S., Ponnambalam, S.G. and Jawahar, N. (2009a) 'A new iterated fast local search heuristic for solving QAP formulation in facility layout design', Robotics and ComputerIntegrated Manufacturing, Vol. 25, No. 3, pp.620-629. 
Ramkumar, A.S., Ponnambalam, S.G. and Jawahar, N. (2009b) 'A population-based hybrid ant system for quadratic assignment formulations in facility layout design', The International Journal of Advanced Manufacturing Technology, Vol. 44, Nos. 5-6, pp.548-558.

Reddy, S.N., Varaprasad, V. and Veeranna, V. (2012) 'Optimization of multi-objective facility layout using non-traditional optimization technique', International Journal of Engineering Science and Technology, Vol. 4, No. 2, pp.564-570.

Rezazadeh, H., Ghazanfari, M., Saidi-Mehrabad, M. and Sadjadi, S.J. (2009) 'An extended discrete particle swarm optimization algorithm for the dynamic facility layout problem', Journal of Zhejiang University Science A, Vol. 10, No. 4, pp.520-529.

Ripon, K.S.N., Glette, K., Khan, K.N., Hovin, M. and Torresen, J. (2013) 'Adaptive variable neighborhood search for solving multi-objective facility layout problems with unequal area facilities', Swarm and Evolutionary Computation, Vol. 8, No. 3, pp.1-12.

Rodriguez, J.M., MacPhee, F.C., Bonham, D.J. and Bhavsar, V.C. (2006) 'Solving the dynamic plant layout problem using a new hybrid meta-heuristic algorithm', International Journal of High Performance Computing and Networking, Vol. 4, Nos. 5-6, pp.286-294.

Şahin, R. and Türkbey, O. (2009) 'A simulated annealing algorithm to find approximate Pareto optimal solutions for the multi-objective facility layout problem', The International Journal of Advanced Manufacturing Technology, Vol. 41, Nos. 9-10, pp.1003-1018.

Şahin, R., Ertoğral, K. and Türkbey, O. (2010) 'A simulated annealing heuristic for the dynamic layout problem with budget constraint', Computers \& Industrial Engineering, Vol. 59, No. 2, pp.308-313.

Samarghandi, H. and Eshghi, K. (2010) 'An efficient tabu algorithm for the single row facility layout problem', European Journal of Operational Research, Vol. 205, No. 1, pp.98-105.

Samarghandi, H. and Jahantigh, F.F. (2011) 'A particle swarm optimisation for fuzzy dynamic facility layout problem', International Journal of Metaheuristics, Vol. 1, No. 3, pp.257-278.

Saravanan, M. and Arulkumar, P.V. (2015) 'An artificial bee colony algorithm for design and optimize the fixed area layout problems', The International Journal of Advanced Manufacturing Technology, Vol. 78, Nos. 9-12, pp.2079-2095.

Satheesh Kumar, R.M., Asokan, P., Kumanan, S. and Varma, B. (2008) 'Scatter search algorithm for single row layout problem in FMS', Advances in Production Engineering \& Management, Vol. 3, No. 4, pp.193-204.

Scholz, D., Petrick, A. and Domschke, W. (2009) 'STaTS: a slicing tree and tabu search based heuristic for the unequal area facility layout problem', European Journal of Operational Research, Vol. 197, No. 1, pp.166-178.

See, P.C. and Wong, K.Y. (2008) 'Application of ant colony optimisation algorithms in solving facility layout problems formulated as quadratic assignment problems: a review', International Journal of Industrial and Systems Engineering, Vol. 3, No. 6, pp.644-672.

Seo, Y., Sheen, D., Moon, C. and Kim, T. (2006) 'Integrated design of workcells and unidirectional flowpath layout', Computers \& Industrial Engineering, Vol. 51, No. 1, pp.142-153.

Sharma, P. and Singhal, S. (2015 accepted) 'A review of objectives and solution approaches for facility layout problems', International Journal of Industrial and Systems Engineering, In Press.

Sharma, P., Phanden, R.K. and Baser, V. (2012) 'Analysis for site selection based on factors rating', International Journal of Emerging Trends in Engineering and Development, Vol. 6, No. 2, pp.616-622.

Singh, S.P. and Sharma, R.R.K. (2008) 'Two-level modified simulated annealing based approach for solving facility layout problem', International Journal of Production Research, Vol. 46, No. 13, pp.3563-3582.

Sirirat, M. and Peerayuth, C. (2007) 'The approximated dynamic programming approach to the dynamic quadratic assignment problem', Thammasat International Journal of Science and Technology, Vol. 12, No. 2, pp.36-39. 
Smith, A.E. and Norman, B.A. (2000) Evolutionary Design of Facilities Considering Production Uncertainty. Evolutionary Design and Manufacture, in Parmee, I.C. (Ed.), pp.175-186, ACDM, Springer, London.

Solimanpur, M., Saeedi, S. and Mahdavi, I. (2010) 'Solving cell formation problem in cellular manufacturing using ant-colony based optimization', International Journal of Advanced Manufacturing Technology, Vol. 50, Nos. 9-12, pp.1135-1144.

Solimanpur, M., Vrat, P. and Shankar, R. (2004) 'Ant colony optimization algorithm to the intercell layout problem in cellular manufacturing', European Journal of Operational Research, Vol. 157, No. 3, pp.592-606.

Souilah, A. (1995) 'Simulated annealing for manufacturing systems layout design', European Journal of Operational Research, Vol. 82, No. 3, pp.592-614.

Sugiyono, A. (2006) 'Cellular manufacturing system aplication on redesign production layout with using heuristics algorithm', IEEE International Conference on Management of Innovation and Technology, 2006, IEEE, June, Vol. 2, pp.940-944.

Suman, B. and Kumar, P. (2006) 'A survey of simulated annealing as a tool for single and multi-objective optimization', Journal of the Operational Research Society, Vol. 57, No. 10, pp.1143-1160.

Surya, P.S. (2009) 'Solving facility layout problem: three-level tabu search metaheuristic approach', International Journal on Recent Trends in Engineering, Vol. 1, No. 1, pp.73-77.

Tasadduq, I.A., Imam, M.H. and Ahmad, A. (2015) 'A hybrid algorithm for optimising facility layout', South African Journal of Industrial Engineering, Vol. 26, No. 1, pp.120-134.

Teo, Y.T. and Ponnambalam, S.G. (2008) 'A hybrid ACO/PSO heuristic to solve single row layout problem', IEEE International Conference on Automation Science and Engineering, 2008. CASE 2008, IEEE, August, pp.597-602.

Thangavel, K., Karnan, M., Jeganathan, P., Petha Lakshmi, A., Sivakumar, R. and Geetharamani, G. (2006) 'Ant colony algorithms in diverse combinational optimization problems - a survey', ACSE J, Vol. 6, No. 1, pp.7-26.

Tompkins, J.A., White, J.A, Bozer, Y.A. and Tanchoco, J.M.A. (2003) Facilities Planning, 3rd ed., Wiley, New York.

Tuzkaya, G., Gülsün, B., Tuzkaya, U.R., Onut, S. and Bildik, E. (2013) 'A comparative analysis of meta-heuristic approaches for facility layout design problem: a case study for an elevator manufacturer', Journal of Intelligent Manufacturing, Vol. 24, No. 2, pp.357-372.

Ulutas, B. and Islier, A.A. (2015) 'Dynamic facility layout problem in footwear industry', Journal of Manufacturing Systems, Vol. 36, No. 3, pp.55-61.

Voss, S. (2001) 'Meta-heuristics: the state of the art', in Nareyek, A. (Ed.): Local Search for Planning and Scheduling, Lecturer Notes in Computer Science, LNAI 2148, pp.1-23.

Wang, G., Yan, Y., Zhang, X., Ning, R. and Wu, Z. (2008a) 'Integrating simulation optimization with VR for facility layout evaluation', International Conference on Information Management, Innovation Management and Industrial Engineering, 2008. ICIII'08., IEEE, December, Vol. 2, pp.389-393.

Wang, G., Yan, Y., Zhang, X., Shangguan, J. and Xiao, Y. (2008b) 'A simulation optimization approach for facility layout problem', IEEE International Conference on Industrial Engineering and Engineering Management, 2008. IEEM 2008, IEEE, December, pp.734-738.

Wang, L., Wang, X., Fu, J. and Zhen, L. (2008c) 'A novel probability binary particle swarm optimization algorithm and its application', Journal of Software, Vol. 3, No. 9, pp.28-35.

Wang, L. and Tang, D.B. (2011) 'An improved adaptive genetic algorithm based on hormone modulation mechanism for job-shop scheduling problem', Expert Systems with Applications, Vol. 38, No. 6, pp.7243-7250.

$\mathrm{Wu}, \mathrm{X}$., Chu, C.H., Wang, Y. and Yan, W. (2007) 'A genetic algorithm for cellular manufacturing design and layout', European Journal of Operational Research, Vol. 181, No. 1, pp.156-167.

Wu, Y. and Appleton, E. (2002) 'The optimisation of block layout and aisle structure by a genetic algorithm', Computers \& Industrial Engineering, Vol. 41, No. 4, pp.371-387. 
$\mathrm{Wu}, \mathrm{Y}$. and Ji, P. (2008) 'Solving the quadratic assignment problems by a genetic algorithm with a new replacement strategy', International Journal of Computational Intelligence, Vol. 4, No. 3 , pp.225-229.

Yang, T., Peters, B.A. and Tu, M. (2005) 'Layout design for flexible manufacturing systems considering single-loop directional flow patterns', European Journal of Operational Research, Vol. 164, No. 2, pp.440-455.

Yang, T., Rajasekharan, M. and Peters, B.A. (1999) 'Semiconductor fabrication facility design using a hybrid search methodology', Computers \& Industrial Engineering, Vol. 36, No. 3, pp.565-583.

Zhang, G.Q., Xue, J. and Lai, K.K. (2002) 'A class of genetic algorithms for multiple-level warehouse layout problems', International Journal of Production Research, Vol. 40, No. 3, pp.731-744.

Zhang, Q., Jiang, C., Zhang, J. and Wei, Y. (2014) 'Application of genetic algorithm in functional area layout of railway logistics park', Procedia-Social and Behavioral Sciences, Vol. 138, No. 1, pp.269-278. 